\section{A CURIOUS FORMATION OF HORSE'S SKULL.} BX ED. J. C. WRAITH.

Near Swan Hill, Victoria, there was found not so very long ago the skull of a horse which tells a pathetic story. When quite young the animal evidently escaped with a piece of manila rope tied tightly around his jaws. In the struggle for existence, the rope became embedded in the bones of the upper and lowe jaws. The opening of the lower jaw, through which the rope passes, at first sight would seem to have been drille but in reality it was worn away by the friction of the rope on the bone.

\section{THE NEW NEMETHY FLYING-MACHINE AND} THE PRINCIPLE OF ITS CONSTRUCTION. BY DR. ALFRED GRA DENWT

More than two years ago a flying-machine built by Mr. E. Némethy, of Arad, Hungary, on the well-known kite principle, was discusse in these columns. In this flying-machine an air propeller was rapidly rotated by a gasoline engine. In the course of the experiments made on this machine, as well as by direct observations, the inventor became convince that on the kite principle a machine could not travel any great distance horizontally, unless an amount of energy quite out of proportion to the effect produced be expended. Birds, on the other hand, no show any visible effort, and as their wings are place in a perfectly horizontal plane, their flying resembles much more the flying of paper arrows than of kites. Némethy, accordingly, decide on imitating, in the novel type of flying-machine which he has just esigned, that other schoolchine which he has just designed, that other school-
boy's toy, the paper arrow, the following rules being followe in its construction:

Any flying body, moving horizontaiiy in the air will undergo a statical drift, equivalent to the weight of the air volume which would be statically displaced in the same interval of time in the case of a vertical fall through the air.

Any body falling vertically through the air will, in its fall, displace statically an amount of air equal to the volume of the body, plus the volume of the air cushion formed below the falling body, the existence of which was discovered by Loessl.

If the weight of the flying body be either equal to or smaller than the weight of the amount of air displace according to the above, the body will float in the air; if this weight be greater, the body will sink, like a body that floats or sinks in water, according as its weight is equal to or else smaller or greater than the amount of water displaced.

For a flying surface m o vi n g horizontally through the air at a spee $v$, the volume $V$ of the air cushion causing the surface to float will be equal to the product of the cross section $f$ of the air cushion by the length $L$ of th same, the latter being equal to the length of the flying surface $l$ plus the speed $v$.

Accordingly, $V=f L=$ $(l+v)$

The weight $j$ of the air cushion being equal to the product of its volume by its specific weight,

$G=v j=f(l+v) j$.

The total weight of a flying-machine therefore should not be greater than the weight of the air cushion $G$.

In the case of a broken flying surface, similar to bird wings, the volume of the bearing surface will be greatest if the wings are incline downward to the horizontal at an angle of 22 eg. $30 \mathrm{~min}$. The angle $B$, according to Loessl, is $45 \mathrm{deg}$. If $a$ be the length of each swinging wing, the cross-section of the air cushion $f$ will be:

$f=2 a \cos \alpha$

$\frac{(a \sin +a \cos \alpha)}{2}$

$f=2 a \cos \alpha \frac{a}{2}$

$(\sin \alpha+\cos \alpha)=a^{2} \cos \alpha(\sin \alpha+\cos \alpha)$. In the case of $\alpha=22$ deg. $30 \mathrm{~min}$., $\cos \alpha(\sin \alpha+\cos \alpha)=$ 1.2071

This figure (1.2071) thus is a constant for calculatng the most favorable magnitude of the bearing surface in the case of the weight and speed of a flying body being given.

When birds move their wings up and down, they swim through the air in accordance with the above

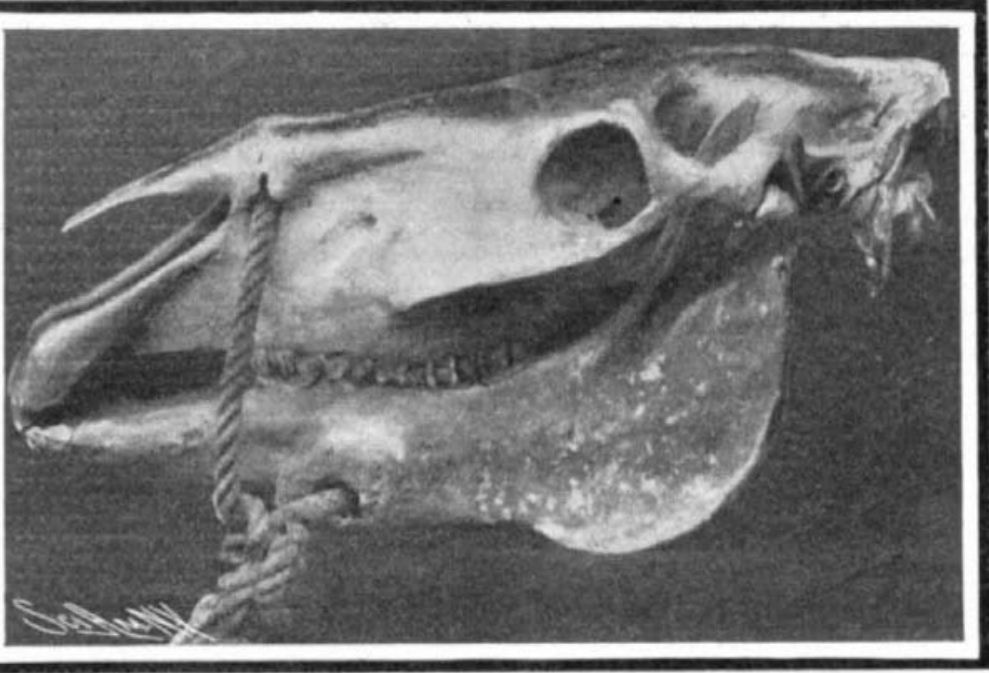

HORSE'S SKULL WITH A ROPE EMBEDDED THEREIN

laws, the horizontai speed necessary for obtaining the statical drift, as well \% the lifting effect in rising being due to the sliding $\therefore$ mponent of the helicoida movement of the wings, while the statical drift itsel may be varied by altering the horizontal speed. Th cross-section of the bearing air cushion is equivalen to the mean value oi the cross sections obtaining in the up and down movement of the wings, is en to the cross-section corresponding to the horizontal position of the swinging wings.

Birds that float in the air, without moving their wings, may équally be said to swim through the air in accordance with the above laws; the surface of attack offered to the wings by the corresponding position of the body, the wings, and the tail of the bird, being a any time such as to drive the bird in the direction desired. As a sailing ship, by virtue of a corresponding adjustment of the sails and the rudder, may be driven even by a back wind acting at sharp angles, the fact that birds in floating through the air may even move

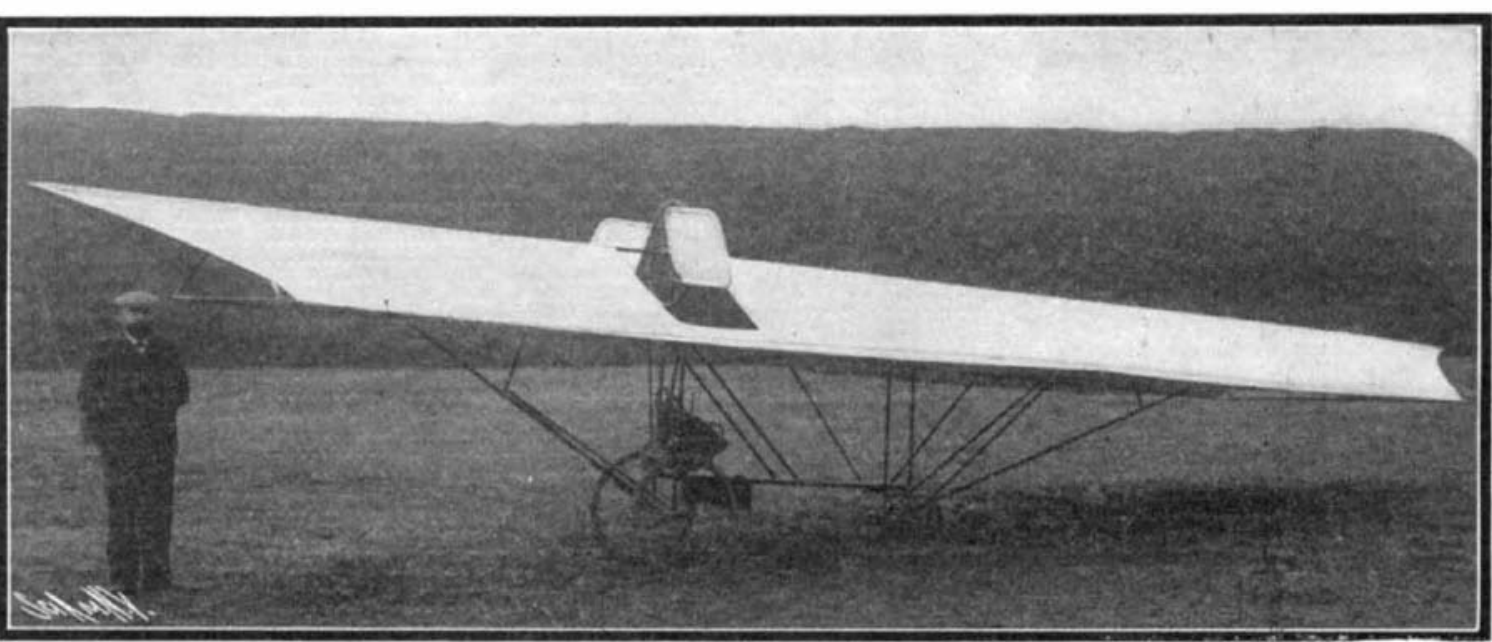

NEMETHY'S NEW FLYING-MACHINE

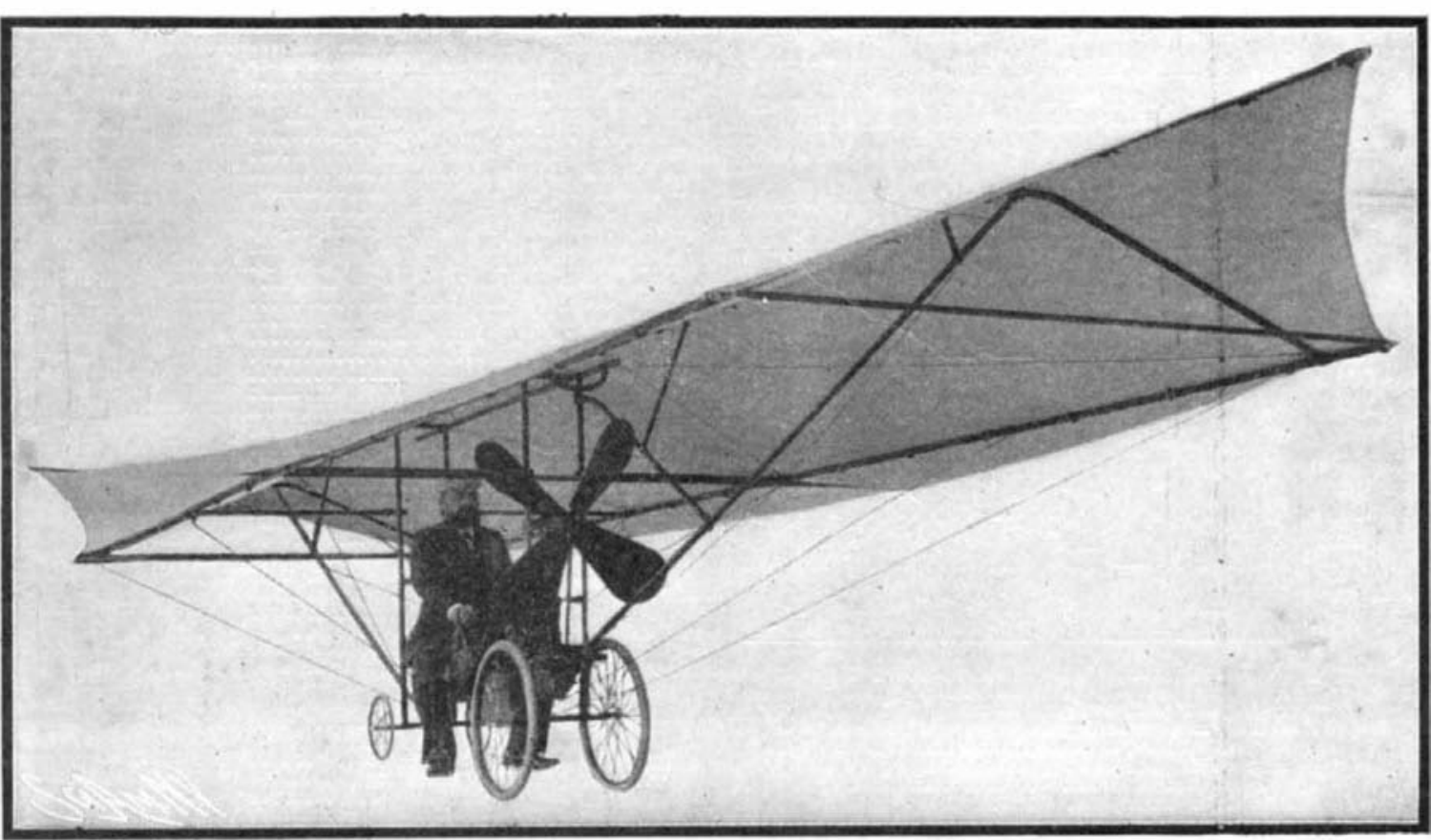

NEMETHY'S NEW MACHINE IN FLYING POSITION. against the wind, is very easily accounted for. A dynamical flying-machine, designe according to the above laws and able to float in the air at a given peed, requires for horizontal flight as much motive power as necessary to drive the floating machine against its front resistance, with any possible strength of the wind, at a speed such as to secure the length of bearing air cushion necessary for the drift. If the motor be stronger than would be necessary for olitaining the floating motion according to the above, the flying-machine, besides floating horizontally, would rise from the ground, the machine being pushe forward on the ground at a higher speed than would be necessary for horizontal flight, and the flying surface receiving a rising direction by lifting the rudder as soon as this increased speed is obtained.

The front surfaces should be as small as possible, and the bearing surfaces so designed as to have the longitudinal axis coincide with the direction of flight. In order to insure a stable floating of flying-machines, constructed according to the above laws, the loa should be so distributed on the latter machine lie below the center of gravi the supporting air cushion, this position being maintained during the flying movement. In order to design a suitable dynamical flying-machine according to the laws enunciated, Mr. Némethy uses a bearing surface resembling an arrow, made from linen, silk, aluminium, or the like, the wings of which should best he incline downward to the horizontal line at an angle of 22 deg. 30 min., so as to obtain the maximum cross section of air cushion, the axis of curvature being parallel to the line of flight.

In order to obtain the necessary horizontal speed, parallel wheels or air propellers may be used, the latter being locate either in the middle of the bearing surfaces or laterally, or else both in the middle and laterally; being driven by an automobile motor or the like. The weight of the whole flying-machine, including the motor, should according to the above be less than the weight of the supporting air cushion.

The airship may be made dirigible by means of a stern rudder, a vertical rudder, and, if necessary, by two lateral rudders. In order to start the airship from the starting slope or cause the airship to rise from the ground or to alight, the inventor provides a set of ground or to alight, the inventor provides a set of
wheels on which the whole machine may roll along. By driving these wheels either by means of the propeller motor or a special motor, either in conjunction with or simultaneously with the air propeller, the whole flying-machine may be used on the roads as an automobile, or else the initial speed may be so rapidly increased as to enable the airship to rise even from an ordinary road.

Although the machine has been constructed, no test has yet been made. Until that test is made, we must forbear criticising the construction.

Extent of the Fish-Hatehing Industry.

We no longer speak of hatching thousands of fry, but of millions and hundreds of millions. The number of eggs, fry, fingerlings, and adult fish distribute by the Bureau of Fisheries in 1902 aggregated one and one-half billion. It is certain that the shad, whitefish, laketrout, and pike perch fisheries, each of vast importance, have not only been saved from entire depletion, but that they have been maintained, chiefly through artificial propagation, at a high degree of productiveness. That these fisheries a $r$ e industries to-day, valued at nearly $\$ 3,000,000$ annually, is due entirely to artificial propagation by the Bureau of Fisheries.From the National Geographic Magazine. 